\title{
Quality Control of Extruded Jelly through a Predicted Enthalpy Profile ${ }^{\dagger}$
}

\author{
Hitoshi Kumagai, ${ }^{*}$ Homi Kurihara and Toshitaka Kobayashi \\ Central Research Institute, Meiji Milk Products Co., Ltd., \\ Sakae-cho, Higashimurayama-shi, Tokyo 189, Japan \\ Received January 11, 1990
}

\begin{abstract}
The method for predicting the enthalpy profile that was developed in the preceding work was applied to the extrusion cooking of jelly. After selecting the enthalpy profile to produce jelly of good quality at a low production rate, the production rate was increased. It was found necessary to obtain an enthalpy profile similar to that at the low production rate in order to maintain good product quality at the higher production rate. For that purpose, the heating capacity of the specified barrel had to be increased and the temperature patterns of the barrels had to be changed. It was ascertained that the method developed in the preceding work was effective for estimating the production capability and offers a strategy for modifying the twin-screw extruder.
\end{abstract}

An evaluation of the enthalpy absorbed by materials in a twin-screw extruder is improtant to determine the best operating conditions, to estimate the production capability of the extruder, and to make improvements to the machine for scaling-up. The enthalpy sources in a twin-screw extruder are viscous energy dissipation and the energy from heaters. The viscous energy dissipation has been directly evaluated by torque measurements. ${ }^{1,2)}$ However, the energy from heaters has not been properly measured on account of the heat loss, although it accounts for a fairly large part of the total enthalpy absorbed by an extruded material. ${ }^{1,3-5)}$ Some authors have developed a model describing the mass temperature in the extruder. ${ }^{4,5)}$ However, it seems that the equations in the model contained some fitting parameters. Consequently, it is necessary to measure the heating energy in order to ascertain that the model properly describes the temperature profile.

In the preceding work, ${ }^{6)}$ the authors developed a method for predicting the enthalpy profile of food materials in a twin-screw ex- truder. Furthermore, the authors investigated the dependence of the absorbed enthalpy on the screw configuration. Those results suggested that the method developed in the preceding work would contribute to the design of screws. ${ }^{6)}$

The purpose of the present study is to apply the method developed in the preceding work to extrusion cooking and to estimate the production capability of a twin-screw extruder.

\section{Materials and Methods}

Materials. Jelly was chosen as the material because the viscous energy dissipation was expected to be negligible in the extrusion cooking of the jelly. In addition, the manufacture of jelly is one of the new applications for the twin-screw extruder. The main composition of the jelly is shown in Table I, the gelatin being of the acid pig skin type (Nitta Gelatin, AP-250). The other materials were commercially obtained, and after mixing under vacuum, the materials were left for two hours at room temperature to allow the gelatin in the materials to swell. The temperature of source material was kept at approximately $25^{\circ} \mathrm{C}$ during the extrusion process.

Instruments. A twin-screw extruder (Kurimoto Tekko

+ Prediction of the Enthalpy Profile of Food Materials in a Twin-screw Extruder. Part II.

* Present address: Department of Agricultural Chemistry, The University of Tokyo, Bunkyo-ku, Tokyo 113, Japan. 
KEX-50) was used in this study, Figure 1 showing a schematic diagram of the experimental equipment. This was almost the same as that used in the preceding work, ${ }^{6}$. except for the needle valve (Sakuramoto SUS316) at the outlet and the pressure gauge (Nishino Seisakusho, $10 \mathrm{Kg} / \mathrm{cm}^{2}$ full scale) at the die section. The pressure gauge was installed to measure the back pressure and to monitor the stability of operation. At first, the number of pipe heaters $(550 \mathrm{~W}, 200 \mathrm{~V})$ in the second, third and fourth barrels and the die was $5,6,6$ and 4 , respectively. The pipe heaters were replaced by $1 \mathrm{~kW}$ heaters, if necessary. The screws used in the twin-screw extruder were mainly forward screws, with four kneading disks and a reverse screw at the end of the fourth barrel to ensure good mixing of the materials. The materials were pumped into the twin-screw extruder from the spare feed point in Fig. 1 with a snake pump (Heishin Kogyo 2NEL S15). The viscous energy dissipation was estimated with the motor load current meter. When the motor load current was $I$ [A] and the screw speed was $r[\mathrm{rpm}]$, the viscous energy dissipation was approximately $0.6 \operatorname{Ir}[\mathrm{W}]{ }^{6}{ }^{6)}$ The product temperature was measured at the discharge port with a thermistor thermometer (Sato Keiryoki SK-1250MC).

Specific enthalpy of the materials. The methods for measuring the heat loss from the barrels and calculating

Table 1. Composition of the Jelly

\begin{tabular}{lc} 
Components & $(\%)$ \\
\hline Sucrose & 13.5 \\
Maltose & 40.3 \\
Gelatin & 9.0 \\
Pectin & 0.9 \\
Citric acid & 0.45 \\
Sodium citrate & 0.27 \\
Starch syrup & 2.2 \\
Sorbitol & 24.0 \\
Water & 9.0 \\
Other ingredients & 0.4 \\
\hline
\end{tabular}

the absorbed enthalpy were the same as those recorded in the preceding work. ${ }^{6}$ ) The temperature of the materials in the extruder was not calculated in the present study because the specific heat of the materials was unknown and only the enthalpy was necessary for the purpose of this study. The electrical energy was measured for $15 \mathrm{~min}$ after attaining the steady state (approximately $10 \mathrm{~min}$ ).

\section{Results and Discussion}

First, the materials were melted batchwise, to prevent the evaporation of water. The materials did not melt below $100^{\circ} \mathrm{C}$, but melted after heating at $109^{\circ} \mathrm{C}$ for $3 \mathrm{~min}$. When the materials were kept at over $120^{\circ} \mathrm{C}$, the browning reaction was accelerated and the gelatin deteriorated. Therefore, the product temperature at the discharge port was controlled near $112^{\circ} \mathrm{C}$ to prevent the deterioration and color development.

Tables II and III show the extrusion con-

Table II. Extrusion Conditions

\begin{tabular}{ccrrrrr}
\hline \multirow{2}{*}{$\begin{array}{c}\text { Run } \\
\text { no. }\end{array}$} & $\begin{array}{c}\text { Feed } \\
\text { rate } \\
(\mathrm{kg} / \mathrm{hr})\end{array}$ & $\begin{array}{c}\text { Screw } \\
\text { speed } \\
(\mathrm{rpm})\end{array}$ & \multicolumn{4}{c}{ Barrel temperature $\left({ }^{\circ} \mathrm{C}\right)$} \\
\cline { 5 - 7 } & 18 & 50 & 130 & 130 & 130 & 130 \\
1 & 18 & 50 & 60 & 80 & 140 & 140 \\
2 & 18 & 67 & 150 & 140 & 140 & 140 \\
3 & 36 & 67 & 80 & 110 & 155 & 155 \\
4 & 36 & 67 & 60 & 90 & 155 & 155 \\
5 & 36 & 67 & 60 & 175 & 155 & $(120)^{b}$ \\
6 & 54 & 100 & 160 & 175 \\
7 & 54 & 100 & 160 & 150 & 150 & 140 \\
8 & 54 & 100 & 90 & 110 & 160 & 160 \\
\hline
\end{tabular}

a 2nd barrel, etc.

b Coolant was used and the electrical energy was not measured.

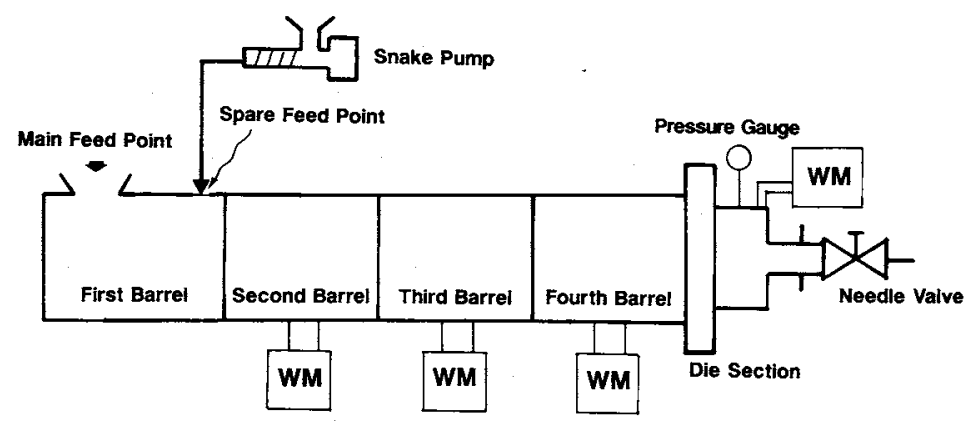

Fig. 1. Schematic Diagram of the Experimental Equipment.

WM, wattmeter. 

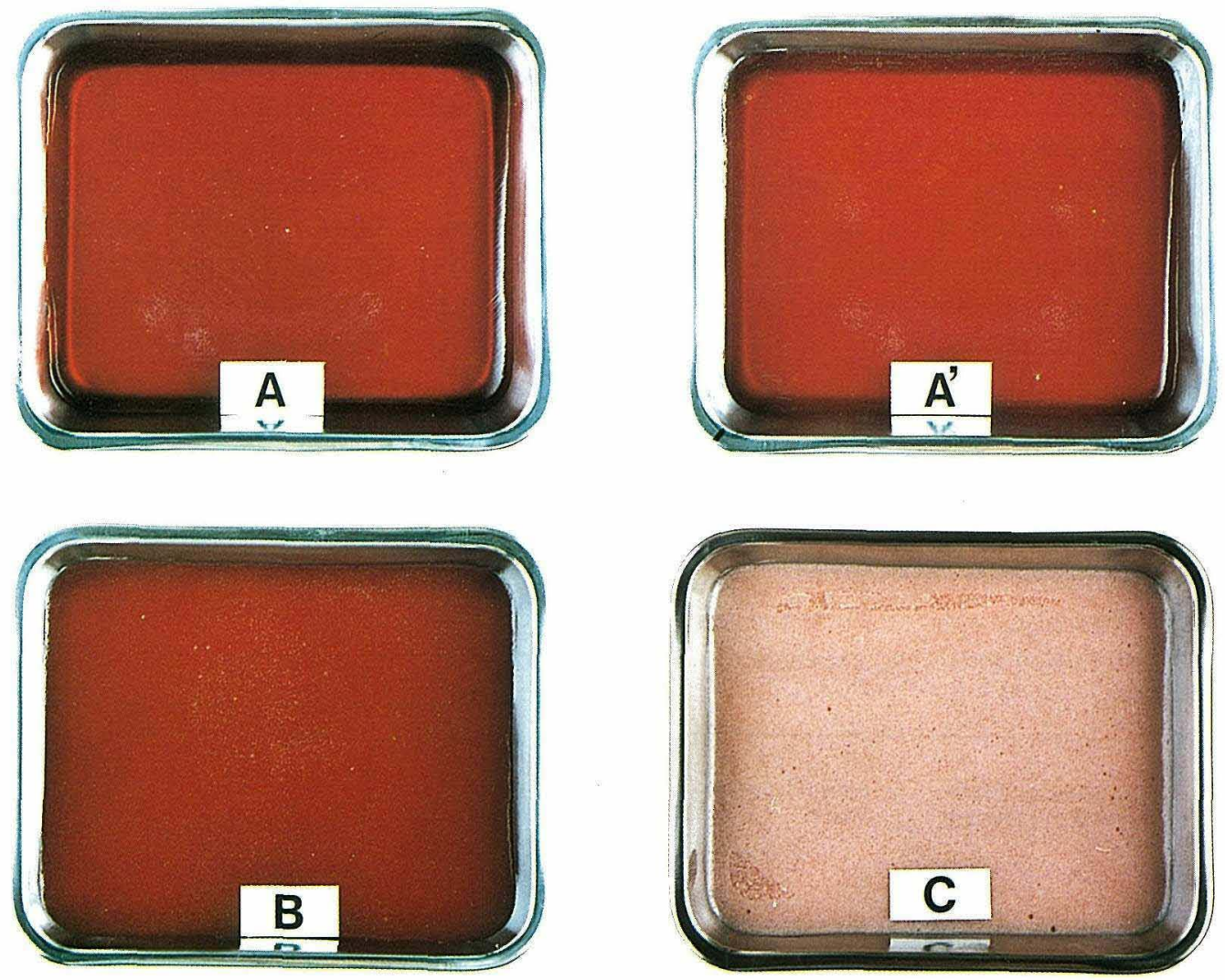

Fig. 2. Photographs of Jelly Extrudates.

Table III. Extrusion Data

\begin{tabular}{cccc}
\hline $\begin{array}{c}\text { Run } \\
\text { no. }\end{array}$ & $\begin{array}{c}\text { Back pressure } \\
\left(\mathrm{Kg} / \mathrm{cm}^{2}\right)\end{array}$ & $\begin{array}{c}\text { Temperature of } \\
\text { products }(\mathrm{C})\end{array}$ & $\begin{array}{c}\text { Quality of } \\
\text { products }^{a}\end{array}$ \\
\hline 1 & 0.1 & 111.8 & $\mathrm{~A}$ \\
2 & 0.1 & 112.8 & $\mathrm{~B}$ \\
3 & 0.5 & 112.9 & $\mathrm{~A}$ \\
4 & 0.1 & $112-113.8$ & $\mathrm{~B}$ \\
5 & 0.1 & $111.4-112.7$ & $\mathrm{C}$ \\
6 & 0.85 & 113.7 & $\mathrm{~A}$ \\
7 & 0.6 & 112.7 & $\mathrm{~A}$ \\
8 & 0.55 & 112.5 & $\mathrm{~B}$ \\
\hline
\end{tabular}

\footnotetext{
a Sensory value.
}

ditions and the experimental results, respectively. The quality of the products was evaluated from the appearance of the melted gelatin, being ranked from $\mathrm{A}$ to $\mathrm{C}$. The difference between the motor load current during extrusion and that necessary for screw rotation

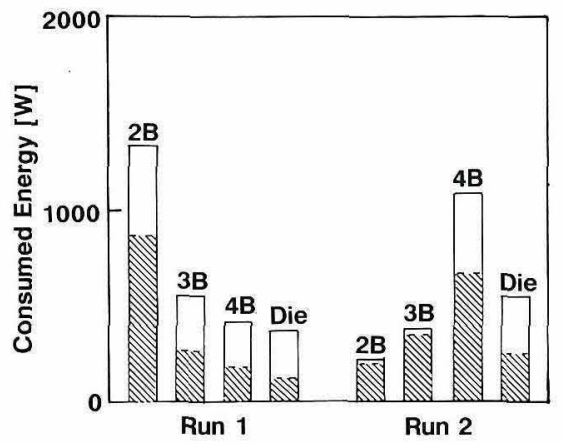

Fig. 3. Heat Loss and Enthalpy Absorbed by the Materials in Each Barrel during Extrusion.

Feed rate was $18 \mathrm{~kg} / \mathrm{hr}$. $\square$, heat loss; $\mathbb{N}$, enthalpy absorbed by the materials.

only was within $1 \mathrm{~A}$, which indicates that the viscous energy dissipation was less than $60 \mathrm{~W}$ and could be neglected in this study.

As Fig. 2 shows, rank A gelatin completely 
melted with good quality, rank $\mathrm{A}^{\prime}$ gelatin mostly melted and approached rank $\mathrm{A}$ after a few minutes, rank $B$ gelatin partially melted with poor quality, and rank $C$ gelatin hardly melted with the poorest quality.

Figure 3 shows the heat loss and the absorbed enthalpy in each barrel at a feed rate of $18 \mathrm{~kg} / \mathrm{hr}$. The product qualities for runs 1 and 2 were $A$ and $B$, respectively. In these experiments, the heating capacities of the second, third and fourth barrels and the die were $2750 \mathrm{~W}, 3300 \mathrm{~W}, 3300 \mathrm{~W}$ and $2200 \mathrm{~W}$, respectively. As can be seen in Fig. 3, the heaters in the second barrel consumed about $1300 \mathrm{~W}$ in run 1 , this value being almost half of the heating capacity in the second barrel of $2750 \mathrm{~W}$. This result indicates that the feed rate could not exceed twice the experimental feed

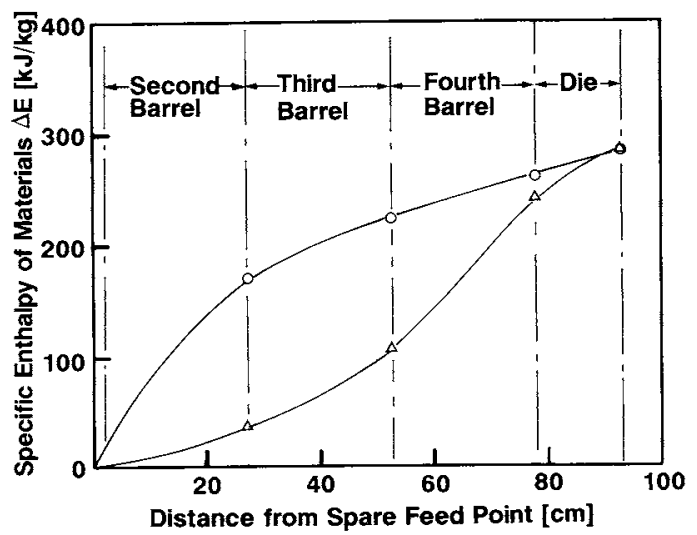

Fig. 4. Enthalpy Profile of the Materials during Extrusion Cooking.

Feed rate was $18 \mathrm{~kg} / \mathrm{hr}$. $\bigcirc$, run $1 ; \Delta$, run 2 .

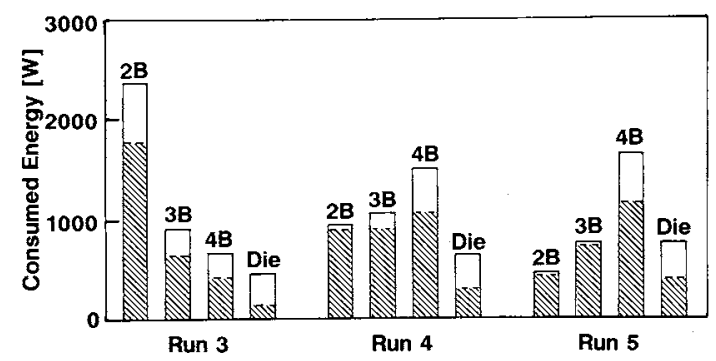

Fig. 5. Heat Loss and Enthalpy Absorbed by the Materials in Each Barrel during Extrusion.

Feed rate was $36 \mathrm{~kg} / \mathrm{hr}$. $\square$, heat loss; enthalpy absorbed by the materials. rate $(36 \mathrm{~kg} / \mathrm{hr}$ maximum) without changing the heating capacity.

Figure 4 shows the enthalpy profile during the extrusion cooking of jelly at a feed rate of $18 \mathrm{~kg} / \mathrm{hr}$. The temperature in both runs was about $112^{\circ} \mathrm{C}$, and the enthalpy reached the same level at the outlet. The quality of the product was, however, better when enthalpy reached a high level at an earlier stage (run 1). This can be explained by the necessity for the materials to be kept at a high temperature for a certain period of time in order to properly melt the gelatin.

Figure 5 shows the heat loss and the absorbed enthalpy in each barrel at a feed rate of $36 \mathrm{~kg} / \mathrm{hr}$. The product qualities of run 3 , run 4

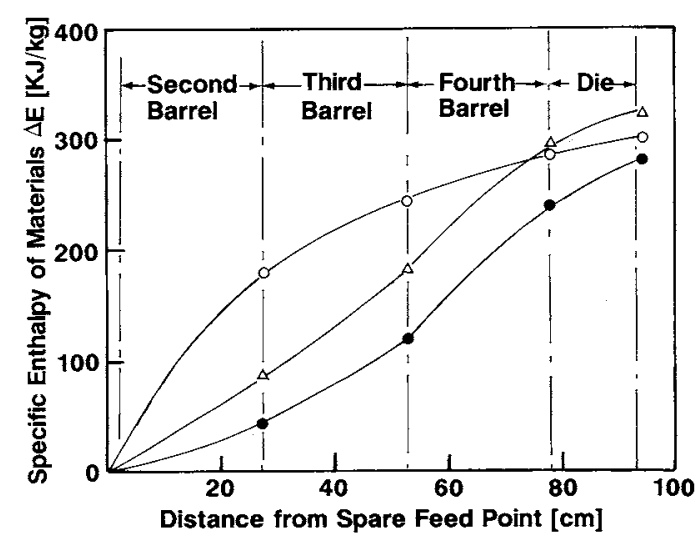

Fig. 6. Enthalpy Profile of the Materials during Extrusion Cooking.

Feed rate was $36 \mathrm{~kg} / \mathrm{hr}$. $\bigcirc$, run $3 ; \triangle$, run 4 ;, run 5 .

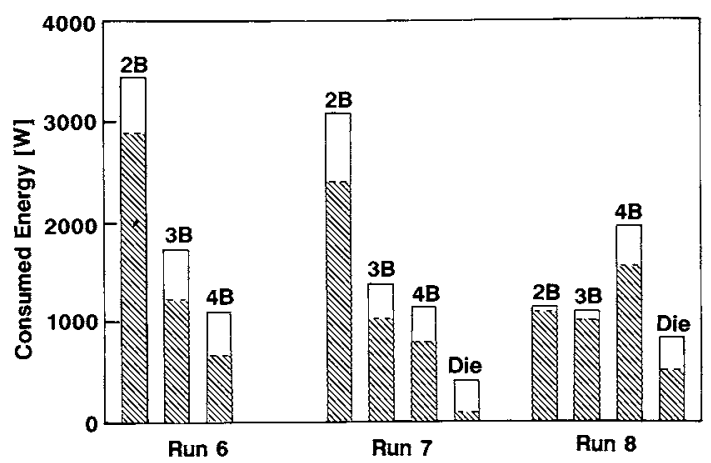

Fig. 7. Heat Loss and Enthalpy Absorbed by the Materials in Each Barrel during Extrusion.

Feed rate was $54 \mathrm{~kg} / \mathrm{hr}$. $\square$, heat loss; $\mathbb{Q}$, enthalpy absorbed by the materials. 


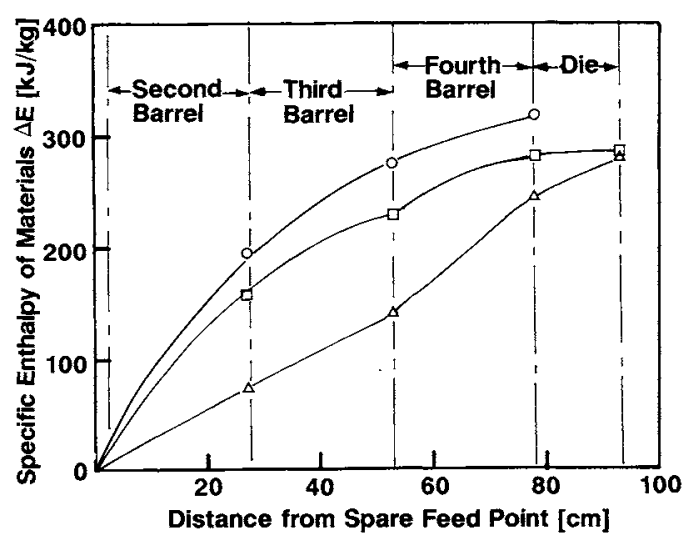

Fig. 8. Enthalpy Profile of the Materials during Extrusion Cooking.

Feed rate was $54 \mathrm{~kg} / \mathrm{hr}$. $\mathrm{O}$, run $6 ; \square$, run $7 ; \triangle$, run 8 .

and run 5 were A, B and C, respectively. Since the energy consumed in the second barrel was considered to reach the maximum heating capacity in run 3 , one of the $550 \mathrm{~W}$ heaters was replaced by a $1 \mathrm{~kW}$ heater.

Figure 6 presents the enthalpy profile during the extrusion cooking of jelly at a feed rate of $36 \mathrm{~kg} / \mathrm{hr}$. The enthalpy almost reached the same level at the oútlet as that for the feed rate of $18 \mathrm{~kg} / \mathrm{hr}$. The quality depended not only on the total absorbed enthalpy but also on the enthalpy profile as in the experiments of Fig. 4.

Figure 7 presents the heat loss and the absorbed enthalpy in each barrel at a feed rate of $54 \mathrm{~kg} / \mathrm{hr}$. As already mentioned, the heating capacity of the second barrel was insufficient for extrusion at this feed rate. Therefore, three $550 \mathrm{~W}$ heaters were replaced by $1 \mathrm{~kW}$ heaters although the voltage had to be reduced to approximately $170 \mathrm{~V}$ due to the rating of the controller in this extruder. It was also necessary to run water through the die in run 6 to prevent any deterioration of the color. Therefore, the energy consumed in the die section could not be measured. If the controller is improved, a further increase of feed rate would be possible.

Figure 8 presents the enthalpy profile during the extrusion cooking of jelly at a feed rate of $54 \mathrm{~kg} / \mathrm{hr}$. The quality of the products was better when the enthalpy level was higher at an earlier stage, as was the case for the experiments in Figs. 4 and 6.

It should be noted that it was necessary to modify the temperature pattern of the barrels in order to achieve an enthalpy profile similar to that at the low production rate. The temperature of the subsequent barrels was usually higher than that of the preceding barrels when the material temperature was increased." However, it was necessary to make the temperature of the preceding barrels higher than that of the subsequent barrels in order to obtain good product quality. This fact was acquired from the data in Fig. 4. The results indicate that the method presented in the preceding study will contribute to the determination of optimal extrusion conditions. Moreover, only the heating capacity of the second barrel needed to be increased for an increase of production rate in this study. This result indicates that the method developed in the preceding study will make it possible to estimate production capability and to offer the strategy for modifying the extruder.

\section{References}

1) F. G. Martelli, "Twin-Screw Extruders: A Basic Understanding," Van Nostrand Reinhold Company, New York, 1983, pp. 102-103.

2) F. Meuser, W. Pfaller, B. Lengerich and A. E. Harmuth-Hoene, Optimization of the Sensory and Nutritional Quality Criteria of Extruded Flat Breads. The Second International Symposium on Twin Screw Extruder for Food Industry, 1988, 7-1-19.

3) J. M. Harper, "Food Engineering and Process Applications," Vol. 2, ed. by M. LeMaguer and P. Jelen, Elsevier Applied Science Publishers, London, 1986, pp. 101-114.

4) W. A. Yacu, J. Food Eng., 8, 1 (1985).

5) D. J. Van Zuilichem, W. J. Tempel, W. Stolp and K. Van't Riet, "Food Engineering and Process Applications," Vol. 2, ed. by M. LeMaguer and P. Jellen, Elsevier Applied Science Publishers, London, 1986, pp. 171-181.

6) H. Kumagai, H. Kurihara and T. Kobayashi, Agric. Biol. Chem., 54, 1975 (1990).

7) "Extrusion Cooking," ed. by the Japanese Research and Development Association for Extrusion Cooking in the Food Industry, Kohrin, Tokyo, 1987. 